\title{
The Nature of Neonatal Experience during Pandemic COVID-19
}

Daved van Stralen, MD, FAAP, Thomas A. Mercer, RAdm, USN

\begin{abstract}
Life abruptly becomes chaotic. This is much like crossing a threshold into a room where we don't belong. The chaotic situation entrains energy and resources, forming a trajectory to cascading failure. The HRO accepts this trajectory and members of the HRO engage in events even as they do not know how to bring it to an end. This is the liminal period, across the threshold and away from our routines. While it appears daunting, if not dangerous, this approach builds on experiences we have had throughout life. HRO methods uniquely shape the engagement that moves through and out of a liminal period. HRO is a trajectory of engagement that fuses now with the experience of then into simultaneous inquiry and redescription. In these states of engagement, the HRO supports using all our mind.
\end{abstract}

\section{"Experience is more than an encounter} or an event. Our presence alone affects the environment, our actions change the environment, and the environment's response changes us."

\section{The Nature of Experience}

Experiences happen to an individual. We "have" experiences in that they happen with "a minimum of regulation, with little foresight, preparation, and intent" (1). Experience is more than an encounter or an event. Our presence alone affects the environment, our actions change the environment, and the environment's response changes us. Reflection gives meaning and salience to our experience. Experience has a form of intimacy in that we don't share the totality of our experience with anyone, how we interpret experience (meaning), nor how we keep and use experience (value). From the Latin root, experiential, "a trial, proof, experiment; knowledge gained by repeated trials," experience contributes to wisdom and identity. A person's experiences become an extension of themselves into the group and help develop new work areas.

When encountering an abrupt change in circumstances, we draw upon experience until we develop the necessary information to use concepts. It is only afterward that we process our experience through concepts for better understanding. When we discuss such an experience, we use concepts that constrain our message.

During a crisis, there is no time to think about each specific bit of knowledge or experience that we depend on to make sense of imperfect information and ambiguity. But having those resources immediately accessible in our minds, we use them in a conceptual decision-making process to frame the decision. We essentially quickly come up with a paradigm of how to solve the problem. It is after the fact that we retrospectively begin to attribute specific reasons for the decisions that we made.

Capt. Chesley "Sully" Sullenberger (personal communication)

"Conscious experience is the awareness of a person's environment as it is perceived. In risky situations, what helps us also hurts us. Such imbalance is continuous while our rules and concepts are fixed and discrete. Experience is what we bring to maintain this balance."

Conscious experience is the awareness of a person's environment as it is perceived. In risky situations, what helps us also hurts us. Such imbalance is continuous while our rules and concepts are fixed and discrete. Experience is what we bring to maintain this balance.

Perhaps the characterization of experience in this article will demonstrate how experiencing the trajectory of events amidst the flux and flow can serve as a foundation for understanding High-Reliability Organizing. We differentiate the use of experience during a crisis from the conceptual clarity that comes after, as described by Capt. Sullenberger.

The essence of life is its continuously changing character, but our concepts are all discontinuous and fixed, and the only mode of making them coincide with life is by arbitrarily supposing positions of arrest therein. With such arrests, our concepts may be made congruent. But these

NEONATOLOGY TODAY is interested in publishing manuscripts from Neonatologists, Fellows, NNPs and those involved in caring for neonates on case studies, research results, hospital news, meeting announcements, and other pertinent topics.

Please submit your manuscript to: LomaLindaPublishingCompany@gmail.com 
concepts are not parts of reality, not real positions taken by it, but suppositions rather, notes taken by ourselves, and you can no more dip up the substance of reality with them than you can dip up water with a net, however finely meshed.

William James (2)

William James (2) describes thought as dealing solely with surfaces while experience can delve into the "thickness" of reality. James (1842 - 1910) (3) and Charles Sanders Pierce established pragmatism as the philosophical study to counter the Kantian view that concepts distort rather than reveal reality. He established Harvard University's psychology department and the first experimental psychology demonstration laboratory. The James-Lange Theory of Emotion describes how the human experience of emotion arises from physiological changes in response to external events. James initially trained in painting, an experiential observation activity that contributes to the Art of Knowledge (4).

Experience is the particulars and relations which have meaning, values, and intention (5). This explains why each of us will have a different experience during the same incident. Thinking is ongoing (6), contextual, and how we experience the environment, how we reach into the environment (7).

We learn about the environment through experience, which provides a way into life's true shape, unconfined by concepts. "The tiniest feeling that we can possibly have comes with an earlier and a later part and with a sense of their continuous procession" (2). Everything is in an environment as an open system subject to the flow of elements and energy. Everything experiences friction and support from other parts of the environment. Each element can be described by both its intrinsic qualities and its external relations with its environment. The traits of a situation include the openness if the system and these extrinsic elements. For example, a seriously ill neonate's care in a rural community hospital differs from the care for an identical, seriously ill neonate in the labor and delivery unit of a university medical center. Each person present in the same situation has a different experience.

Direct acquaintance through experience and conceptual knowledge complement each other, filling in the gaps natural to each. This experience that reveals the nature of things is critical to support the validity of intellectual knowledge. Experience as direct, unmediated awareness of events is knowledge by acquaintance (8), a foundational principle of HRO.

We cannot know how someone individually experiences an event, even when we are adjacent to them. Sensations are experienced singly, together, fluctuating as attention fluctuates, items in memory entering or dropping out (2). To have "knowledge by acquaintance," we must have a cognitive relation with the person, direct and unmediated awareness of what they are experiencing (8), including their cognition. This is not a trite statement. When we accept others' experiences, we gain a more reasonable idea of the sum of experiences in the event and a better appreciation of life.

Introducing students in training to a basic truck driving maneuver, which is the same worldwide, the instructor must be aware of each student's experiences and motivations, how they react to instructions, and how they react to the truck's movement. The real teaching and learning event occurs when the student synthesizes a new experience from their previous experience (Errol van Stralen, polymath, educator). In this manner, instructional learning becomes a preparation for experiential learning. "Maybe, HRO is a trajectory of engagement that fuses now with the experience of then into simultaneous inquiry and redescription," Karl Weick (personal communication).

While the leader may have developed close relationships with subordinates, the cognitive and affective responses to an emotionally charged event can be indirect, delayed, or become dormant ( 9 , 10). The leader can become familiar with the cognitive styles experienced individuals may use, such as model- or concept-based, pragmatism, stress- or fear-based, or allostatic challenge.

We also cannot experience the sum-total of events around us because the experience is disseminated, distributed, and incompletely unified. The belief that one's experience is shared by or subordinate to others risks negating their experience. This absolutist view happens in healthcare when a physician or surgeon negates others' experience, removing their experience from consideration. It then becomes the dominant account, driving other views to become hidden voices with loss of the expertise the leader could have deferred to (11).

\section{"Considering the world as rational, coherent, and predictable removes the sense of experience, contributing to reliance on discrete concepts and introducing expectations into operations. Through irrationality, a constituent of experience, and our reluctance to simplify, the "actual world" reveals discontinuities, discrepancies, and disruptions."}

Considering the world as rational, coherent, and predictable removes the sense of experience, contributing to reliance on discrete concepts and introducing expectations into operations. Through irrationality, a constituent of experience, and our reluctance to simplify, the 'actual world' reveals discontinuities, discrepancies, and disruptions. Thus, our irrationality becomes the conduit necessary for the identification and engagement of early heralds of failure. At worse, the charge of irrationality is used to gain conformance from others.

Experience has its own internal rationality that appears irrational to the outsider. Everyone acts in a way that makes sense to them. Some will apply external rationality to a situation, for example, "What were they thinking?" This phrase diminishes the efforts of others and prevents learning from the experience of others, a necessary step in generating safety. One author reframed the situation, "What the person did was correct. It was what I would have done." Then, the question, "What made the person think it was the right thing to do?" reveals information otherwise unattainable and produces interventions to generate greater reliability and safety. 
The drive to conjure a satisfactory reason for an irrational act comes from our need for self-preservation. If the person acted or thought in a way "I wouldn't," and since "I don't do that," then "I am safe." This becomes striking in the NICU when well-meaning family and friends ask the mother if she did "X" during her pregnancy. They are searching for anything that makes them feel safe; anything the mother did that they wouldn't do, means they are safe.

\section{"Experience is how we transform reality, how we transition the actual world to a possible world. Regardless of role or status, the individual has the experience and transforms reality. One's presence constitutes experience."}

Experience is how we transform reality, how we transition the actual world to a possible world. Regardless of role or status, the individual has the experience and transforms reality. One's presence constitutes experience. When one author (DvS) exited the fire rescue ambulance as one of two on the unit, his presence changed the scene - countenance, stance, or walk. It didn't matter if the crowd was angry, apprehensive, or frightened. We could direct their feelings or leave them uncontrolled to continue cascading toward an uncertain result. The simple process and content of questions changed their experience. Asking what the person did could make them feel responsible, as described above, impeding information flow. Concepts assumed to be necessary for evaluation and management could misdirect or mislead our inquiry. "Vital or direct experience, as man's experience, is more valuable; and is truer in the sense of worth more for other interpretations, for the construction of other objects and the basing of projects upon them" (12).

John Dewey (1859-1952) was a psychologist who criticized the reflex-arc for animal behavior as simplistic because animals continuously interact with the environment in cumulative and modifying ways; educator, initiating the University of Chicago Laboratory Schools; and philosopher, identifying the importance of experience in "cultural pragmatism."

\section{Concepts and Concreteness}

Concepts provide the elements for comparison, standardization, and quantification. Immanuel Kant (1724-1804) presented concepts from specified delimited categories and argued against scientists' efforts to transcend thought and experience. He posited that knowledge is accessible and contained within the limits of these categories. Therefore, it is possible to know the world and its phenomena. He argued against the value of experience. Today we readily reject the details of his ideas without realizing his work formed science as concepts and logic.

His influence spans the $18^{\text {th }}$ Century to today in the physical sciences, the life sciences, modern mathematics, mathematical logic (13), and social sciences (14). Our use of "spatio-temporal relations" comes from his idea of space and time as entities that structure experience distinct from objects themselves. The formulation of "social knowledge" is how Kant mediated between the facts and thought of reason and morality's values and action (14). Kant's Critique of Pure Reason (15) is one of the most influential works in philosophy.

Kant developed the idea that knowledge as facts and concepts are included in preformed (a priori) categories and linked rigorously by laws of formal logic $(16,17)$. Something cannot exist except for its inclusion in a category, therefore placing a limit on knowledge. Kant's influence on the definitions of knowledge and the validity of science directly influences how we experience science and, by extension, how we experience emergencies in the NICU.

One view of Kant is that living in an environment of chaos simplified thinking for us, separating the objective from the subjective and delimiting knowledge to specified categories connected by scientific logic. Kant responded to an environment of chaos, particularly in response to the 1755 Lisbon, Portugal earthquake that killed 40,000 people, by creating metaphysical order for knowledge and behavior $(18,19)$. Kant also argued earthquakes were a natural phenomenon and not punishments from God and may have started a humanitarian approach to disasters (20). Perhaps Kant separated belief from reason because of concurrent disasters. HRO, through experience, unites belief and experience.

With modifications, the Kantian view of concepts continues into the sciences with a priority of beliefs developed from concepts over beliefs derived from experience. James, Dewey, and Whitehead argued against the primacy of concepts when applied to actions. Today, we encounter healthcare professionals who, standing at the bedside with us, refuse to believe what is happening because it is not in a concept known to them or will not accept the experience because it does not fit a known concept. However, in a liminal state or High-Reliability Situation, the gap between structured theories and an unstructured situation makes it difficult to rely on reasoning. In our discussions with Karl Weick, we believe that $\mathrm{HRO}$ shrinks the size of that gap.

Dewey and James contested Kant's emphasis of concepts over experience, that knowledge did not exist beyond concepts and his categories $(19,21,22)$. The theory provides unity of experience by general laws and the constitution of experience. For Kant, this determines the completeness (unity) of knowledge (13).

We do not experience concepts; rather, concepts emerge from experience. Concepts are representations of reality; we must not mistake them for reality. "What really exists is not things made but things in the making" (2).

When we conceptualize, we cut out and fix, and exclude everything except what we have fixed. A concept means a "that-and-no-other"... In the real concrete sensible flux of life experiences compenetrate each other so that it is not easy to know just what is excluded and what is not... Past and future, for example, conceptually separated by the cut to which we give the name of present and defined as being the opposite sides of that cut, are to some extent, however brief, co-present with each other throughout experience. The literally present moment is a purely verbal supposition, not a position; the only present ever realized concretely being the 'passing moment' in which 
the dying rearward of time and its dawning future forever mix their lights. Say 'now', and it was even while you say it.

William James (2)

'Concepts can be 'counterfeit abstractions' that imitate some, but not all, of the differentiated flux produced by attentive HRO practitioners, (Karl Weick, personal communication). That is the trouble with experience, when is a concept useful, when it is a counterfeit abstraction, and when is it misplaced concreteness? Alfred North Whitehead (23) describes "the accidental error of mistaking the abstract for the concrete. It is an example of what might be called the 'Fallacy of Misplaced Concreteness." But concepts can be intentionally used as concreteness. James (24) described how one could identify a salient or important feature to use it as the group's classifier, negating other attributes in favor of this single trait. "Abstraction, functioning in this way, becomes a means of arrest far more than a means of advance in thought." It becomes too easy to substitute a virtual world from concepts for the actual world is by way of the fallacy of abstraction.

\section{"HROs operate within the flux and flow of} not only operations but the environment. Rather than a direction, operations do operate in a direction, such as a premature infant is admitted, the mechanical ventilator is managed, the lungs heal, the infant can be discharged home. "

HROs operate within the flux and flow of not only operations but the environment. Rather than a direction, operations do operate in a direction, such as a premature infant is admitted, the mechanical ventilator is managed, the lungs heal, the infant can be discharged home. But disruptions change the arc, something the neonatologist engages intending to redirect the new trajectory. Using abstractions for concreteness is a fallacy more likely relied on at a distance; the moving trajectory of events reduces this severe concreteness (Karl Weick, personal communication).

The misplacing and fixing of abstractions is a big issue. Misplaced concreteness is the problem. and your emphasis on moving, flow, trajectory, reduces isevere concreteness.) I'm studying a disaster that sank the container ship El Faro. As they are entering the eyewall of hurricane Joaquin, without knowledge of winds and at 4 AM in darkness, the captain says, 'this is a typical winter day in Alaska.' and sticks to his route straight toward the eye. Ship (790 feet long) capsizes 3 1/2 hours later drowning all 33 crew. Typical day is a severe abstraction. Karl Weick (personal communication)

The problem with models. Experts do not use systematic patterns yet tend to detect errors faster and with greater accuracy than students (25). "There is a leap, a discontinuity, between the competent level and the proficient and expert levels. If experts are made to attend to the particulars or to a formal model or rule, their performance actually deteriorates" $(26,27)$. To become truly proficient, we must drop rules, which are the tools of professionals. This is similar to Weick's adage to firefighters to know when to drop their tools (28). It is the experience that gives the wisdom when to drop them. In the Mann Gulch wildland fire disaster, fire foreman Wagner Dodge says, "Drop your tools." His crew held onto their tools. Thirteen men died. Using experience as the frame of reference, experiencing a fire burning up a steep slope on a hot day and you are near the ridgeline, what would you be experiencing? What is the experience of holding a fire tool? When does the tool protect you, and when does it kill you? Is there a sharp line? Experience that when you stand next to the isolette with a dying baby. Experience decompresses decisions even as alternatives gain gravity while you work to gain life. At times, we can only communicate through experience.

\section{"Experience decompresses decisions even as alternatives gain gravity while you work to gain life. At times, we can only communicate through experience."}

\section{Experience has purpose}

Our experiences in the moment contain story arcs that connect us to our past to others and form extensions into our future. For John Dewey(29), when we perceive our work as aesthetically pleasing, we create experiences in which the subject is new. Our work then becomes an endeavor with those around us. This is the art of neonatology as experienced (4). Dewey contrasts this with inchoate experience in which we are distracted and do not complete our course of action. "For Dewey, life is a collection of histories, each with their own plots, inceptions, conclusions, movements and rhythms" (29). Each has a unique pervading quality. Our experience becomes our identity and is the source of our pride.

Experience as an endeavor. Dewey holds that someone who aesthetically perceives a work will create an experience in which the subject is new material. Experiences are processes of doing or making. Experiences are the assets people bring to a program. Experiences are also their identity and source of pride in their own accomplishment rather than in the team or organization. This goes to the aesthetic from Dewey: Art and experience (4) are what makes an experience an experience by uniting them in the same relation. When the experience runs its course and problem solved, or we have a resolution, it is more a consummation than a cessation. This carries a quality of self-sufficiency, and our experience gives meaning to our life (29).

Our experiences in the moment contain story arcs that connect us to our past, to others and that form extensions into our future. For John Dewey (29), when we perceive our work as aesthetically pleasing, we create experiences in which the subject is new. Our work then becomes an endeavor with those around us. This is the art of neonatology as experienced (4)]. Dewey contrasts this with inchoate experience in which we are distracted and do not complete our course of action. "For Dewey, life is a collection of his- 
tories, each with their own plots, inceptions, conclusions, movements, and rhythms. Each has a unique pervading quality. Our experience becomes our identity and is the source of our pride.

\section{"Through the Art of Neonatology, neonatologists care for their patients and gain life."}

Experience as inquiry. "Inquiry is the behavioral response of a reflective organism to its environing conditions, taking place in the world, not just within the mind," John Dewey (30). Truth is related to experience rather than extrinsic to experience. Truth, then, is a process of inquiry (29). Whereas in science, truth is objective and can be settled to be available for the use of others. One of the five values is honesty (DvS book), described by one of the authors (TAM), where what a person says represents what is happening. In the HRO process, knowledge and truth never become settled.

John Dewey believed in keeping continuity between everyday experience and art (29). In fact, the art of neonatology extends the experience of life into the NICU and the methods of cognition into everyday experience. This develops at a deeper level than acting as healthcare professionals in public. Rather than maladaptive responses to the stress vectors novelty, uncertainty, uncontrollability, or a fear vector (31), individuals more readily adopt allostatic or prosocial responses. Discrepancies and disruptions then become early heralds of failure that trigger engagement.

During a routine state review where one author (DvS) was an attending, the auditor asked facility leaders a question about the mechanical ventilators. Observing the discomfort as the leaders called for a senior administrator, a bedside respiratory care practitioner (RCP) hurried to the room and announced, "Hi! I'm an RCP. Can I help?" The RCP correctly answered the question. This is not a story of a bedside caregiver besting leaders. The RCP joined the group with a sincere desire to help. Rather, the RCP had incorporated into experience the extensional traits of $\mathrm{HRO}$ regarding the ecology of fear and the art of medical care $(4,32)$.

Experience as meaning. Experiences are the assets people bring to a program. Experiences are also their identity. Our experiences in the moment contain story arcs that connect us to our past, to others and that form extensions into our future. Consummating an experience or solving a problem gives us meaning (Letty) and a sense of self-sufficiency. For John Dewey (29), when we perceive our work as aesthetically pleasing, we create experiences in which the subject is new. Our work then becomes an endeavor with those around us. This is the "art of neonatology" (4) as experienced. Our experience then becomes our identity and is the source of our pride.

Theories can isolate the organization from the environment in the manner that appreciation of the theory of HRO supersedes the appreciation of the experience of HRO. Experiences are the source of pride for the individual in their own accomplishments rather than the team or organization's accomplishments. We give meaning to our personal efforts through experience.
Experience as learning. Our experiences are developing series and circuits of activities rather than disconnected sequences. Learning builds on complementary experiences and prepares us for expected experiences. This is the affective domain (33) of how learning will help the individual. One of the authors (DvS) held that "what is taught today should explain yesterday or be used tomorrow." For Dewey (Letty), "inquirers" move from the phase of dissatisfying doubt toward satisfaction of resolving a problem and gaining meaning.

Experience as support. "You can do it." These words, said in person, provide a deep, intimate level of support that carries in memory for decades. One author (TAM) heard it from his captain before his first combat mission over North Vietnam. The other author (DvS) heard it from his fire station commander, Bill Corr, during a difficult period of rescue calls working with a novice firefighter. A paramedic (who dropped out of medical school for the fire department) responded to his first cardiac arrest patient, who was his father. He looked to his captain, also the surgeon who trained him, and his captain said, "You can do it." His father survived. One author (DvS), as medical student body co-president, sat on the stage to welcome the first-year medical students. As the last speaker, he

\section{"Negative space is the space in a painting intentionally left empty to bring attention to the subject, the subject being the positive space."}

heard all the speakers express how difficult the first year is. Standing up to speak, he discarded his talk and said, "You can do it." A student came to him one year later and said those words helped him through the first year.

Experience as success. The CEO of a pediatric nursing home wanted to improve the facility in terms of patient care and increased census. Jeff Lewis, the new administrator of 18 months and knowledgeable about HRO, met with staff to identify areas of improvement. Bedside staff did not know what to do or how to do it. Managers believed it was a trick to make them look bad. The only role Lewis assumed was approving projects. The subsequent state survey found no deficiencies; a record kept for five years. US News and World Report recognized the facility as one of 27 out of 15,500 nursing home facilities in the nation having zero deficiencies, recognition the facility sustained for five years. Experience as inquiry generated organizational learning and developed meaning within the experience of subordinates, from management to the bedside caregiver. Lewis, without additional funding, had used $\mathrm{HRO}$ as engagement and self-organizing improvisation to initiate his program, which culminated in national recognition.

The need for experience. One author (DvS) has attended conference lectures that demonstrated the effects of inexperience on the part of the speaker. Several lecturers introducing themselves with "I've seen everything" (having seen a lot, neither author uses this phrase). Lecturers on safety presenting scenarios where the operators or patients were severely injured or killed, followed by "What were they thinking?" (Standing at the scene in the presence 
of family, friends, and colleagues, one can understand, DvS.) Lecturers using movie or television comedies with large families to describe the home conditions of ethnic multi-generational families. (Inside the house looks crowded but does not feel crowded; only love and affection, DvS.) Lecturers used notorious criminals or incarcerated family members who claim they are innocent as foils as a reason to deny home care (criminals show love for their families, and wrongful convictions and false confessions are overrepresented with people of color, DvS). In every lecture, the entertained audience laughed.

\section{"Perception may seem dependent on definitions, but definitions come up short in the turmoil of the liminal space. Descriptions of how something is used, an action performed, or a situation experienced all carry meaning."}

These situations describe inexperience on the part of the professional rather than malicious beliefs. It is difficult to learn as cognitive information lends itself to these views while affective information counteracts them. The fallacy of abstractions impairs reflection about the experience as the abstraction takes precedence over the actual world. Abstraction too easily changes a possible world to become considered a real world. The inexperienced person then believes that is how the world is. Neonatology, on the other hand, has taken a different approach and gained life through engagement.

But there are times our experience and concepts seem to fail us. We are in a place we are not supposed to be. We don't know how to get out. Like tarrying in a hallway, an elevator with a jammed door, or standing alone in the middle of a large reception. These are meant to be places of a threshold meant to pass through to another, better place. Sometimes we cannot. For parents, this is the NICU.

\section{Liminal Zones, Liminal Experiences, and Liminal People}

The present moment is our passing from the past to the future. Some rooms in buildings such as hallways, stairwells, and elevators serve as passages and are not designed for people to remain any length of time. Liminal zones describe the time when the future hasn't arrived before you pass to the next room. These are episodes, seemingly motionless, between what was and what will be.

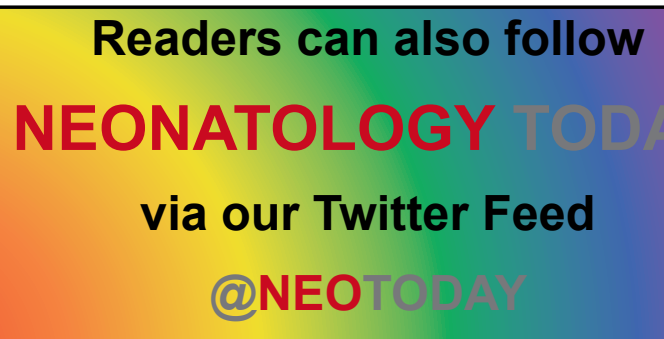

Sometimes these are "thresholds" (liminal from the Latin, limin, threshold) to a new beginning. Graduations, full recovery from major illness or injury, and major accomplishments all mark a change in our lives. From our knowledge and experience, we have a repertoire of actions necessary to move through these transitions and reach our goals. This is about good planning and preparation.

Liminal times and liminal spaces are concepts from anthropology, described as "rites of passage" when the initiate has entered a new space, leaving behind the characteristics of a previous status and not yet moving on to the new status's characteristics. The old rules do not apply, and moving to the new rules is not assured. There are three phases, each with its own meaning, but the middle passage describes the sense of not belonging with the inability to act.

A rite of separation is characterized as a metaphorical "death."

Remove norms from the previous status without receiving the new status's norms; the passage is in doubt, making it the apparent potentially dangerous part of the ceremony.

Rejoin the community in the new status.

However, when structure and activity become random, we lose context. Unfamiliarity and loss of context become disorienting or overwhelming. At other times, the context or structure is too complex or disordered for us to proceed. Prudence and an abundance of caution may overtake reasoning, and we hold back. Time compression or self-protection may overtake reasoning, and we strike outward using forceful action - verbal or physical. Though this may feel like a failure and even appear like a failure to outsiders, it is not a failure. We have entered a liminal space, a common if unrecognized experience in routine life and a characteristic of nonroutine life. The ecology of fear $(32,34)$ creates widespread and unrecognized liminality. The fear of error, litigation, failure, etc., creates the liminal space, and, similar to liminality described in this article, there is no assured means to escape and no way out.

\section{"However, when structure and activity become random, we lose context. Unfamiliarity and loss of context become disorienting or overwhelming. At other times, the context or structure is too complex or disordered for us to proceed. Prudence and an abundance of caution may overtake reasoning, and we hold back."}

"Experience is the rite of passage. All certainties are removed. The certainty of past behaviors and treatments are permanently gone. Acceptance and any new behaviors and treatments are not present and may not be. There are no standard behaviors and treatments during the experience. This creates the delicate uncer- 
tainty and malleable state of the individual. Anything that happens can change the person's core being" (21).

These characteristics align with the NICU events from an abrupt change when learned behaviors no longer operate and grave, possibly hidden threat is present. This second stage, the verge of the threshold or "limin," gives liminality its name. This area of liminality, whether it is space or time, we call the "liminal zone."

Liminality is in-between BECAUSE you leave the familiar and enter an environment with no solution. The solution you generate creates your next actual world from the possible worlds that existed as you entered. So, it is in-between your actual world and the next actual world that you generate from the possible worlds. If there were no possible worlds, you would not be in-between, and if both worlds are actual worlds, you would not be in-between.

Liminal spaces are like areas of a building that are meant for transit or storage. Dwelling in a strange room for any length of time is uncomfortable, especially if you are alone. Liminal spaces can also be social spaces like a party or any gathering where you are unfamiliar with the people. Try standing in the middle of a social gathering without anything in your hands. The social isolation becomes palpable. (Though one of the authors (DvS) did this at a military special operations medical conference. Rather quickly, individual army medics approached to talk. One invited the author to join his table for the conference dinner.)

\section{"We question if plans and planning, the commonly accepted methods, are the most effective approach to enter or exit a liminal space. It appears the hallmark of liminal space is the uncertainty of what actions will be successful.. This is what makes planning difficult."}

We question if plans and planning, the commonly accepted methods, are the most effective approach to enter or exit a liminal space. It appears the hallmark of liminal space is the uncertainty of what actions will be successful. This is what makes planning difficult. Engagement, we define, is the act of approaching and entering liminal spaces. In these situations, sometimes, all we have are observation and action (4). Engagement describes actions taken without certainty that they will succeed. These are reasoned actions that generate information while building structure and controlling energy. This is "learning-by-doing" and not "trial-and-error." In a situation fraught with ambiguity and equipoise, the only error occurs when one stops acting, and the only failure that occurs is withdrawal. A movement toward the best achievable end-state is the goal.

In extreme forms, this becomes a rebirth as a reciprocal change to the individual is significant. At the milder level, it is substantive learning. That is, we have changed our way of thinking.

\section{Liminality is Experience}

"If your body is moving faster than your brain can think, then slow down. If you feel your eyes glaze over, slow down," William J. Corr, Captain of the Los Angeles Fire Department (personal communication). Corr was describing the shift from engagement to the disengaged thought that can occur in the liminal zone. We describe engagement below as experience entering the liminal space. Corr, acknowledging that events can overcome us, advises one to slow down to regain the senses.

Severe concreteness or reliance on abstractions signifies when someone has mentally entered a liminal zone. Severe concreteness arises when abstract thought becomes impaired from the loss of executive functions in the prefrontal cortex function. This is a primary stress response $(31,35)$.

Kant's response to the energy of chaos was to bring calm, separating the subjective from the objective with concepts (19) and separating science (practical reason) from belief (pure reason) (14). But concepts are a technical system independent of the situation and experience. They are used with intention from outside the liminal space to give organized commands to form a structure in the chaos. The rigidity and wishful thinking fail in open systems faced with entropy. Rather experience as engagement by entering the liminal space with nonlinear interactions with local effects builds structure. This is the self-organizing improvisation of $\mathrm{HRO}$ $(36,37)$. It can be difficult working in an emergency with someone who pursues concepts. Methods are described elsewhere (31, 35).

Abstractions are more than abstract thoughts, and the future is an abstract thought relative to the time scale. Abstractions include rules, cliches, maxims, principles, models, concepts, and theories. Concepts are representations of reality. They must not be mistaken for reality. "Concepts can be 'counterfeit abstractions' that imitate SOME but not all of the differentiated flux produced by attentive HRO practitioners," Karl Weick (personal communication).

Liminal people. Those who have sustained liminal experiences find that their values and characteristics have changed (38). They are often marginalized from the dominant account, for example, combat veterans. Combat veterans are reluctant to use and share their experiences, particularly those from the Vietnam era, because of their liminal wisdom (38). Reasoning from past experience to apply to present experience seems irrational since the situations are not identical. The combat veteran learned that experience is a process and engagement that relies on constant reciprocal feedback to learn what works through action. Mastery of concepts, a Kantian approach, becomes the dominant account, suppressing interpretations of those constructing the reality. Liminality nor experience, as arts (4), cannot be mastered.

\section{Engagement}

Passage through the liminal space is active rather than passive. From the "concept stance," one would expect planning to prepare a person and plans to guide actions. Sean McKay (37) answered the criticism of improvised plans regarding the fire department response to a terrorist shooting. The department moved 14 patients from the triage site in 18 minutes with no deaths. "They didn't improvise a plan. Their plan was improvisation." 
Despite the emphasis on evidence-based approaches in numerous fields, there has been no controlled experimentation for best practices to engage an unstructured situation in flux. One area that relies on HRO, high angle rescue, requires all rescuers to be secured by rope, plans for engagement in liminal spaces, adapting equipment, and training for situations where equipment and training are not sufficient (39). They follow Karl Weick's dictum (personal communication): "If it's liminal (which it often is), engage with all your mind."

\section{"Engagement describes the approach and experience with a situation when the operator does not know what will work. “I don't know what is happening, but I know what to do." - a Los Angeles Fire Department firefighter."}

Engagement describes the approach and experience with a situation when the operator does not know what will work. "I don't know what is happening, but I know what to do." - a Los Angeles Fire Department firefighter. "HRO uniquely shapes the engagement that moves through and out of a liminal period," Karl Weick (personal communication).

Engagement reduces certitude. Certitude is an early herald of failure. Engagement at the point of contact, where line workers operate, is nearly always a liminal space. Neonatal physiology, parents, families, and the local circumstances are never the same. While creating a PICU, Ron Perkin would tell staff he didn't care what they did...they just had to stay at the bedside (DvS, personal communication). That is, engagement continued past the point of action, continuing through observation for complications, effectiveness, and sustainability. The further away one moves, the consequences of certitude decrease. In some sense, certitude can be a hazard from limited experience in the field or with higher status.

Previously, we (40) described how engagement bridges the gap between theory and practice (40) and between discrete concepts and continuous perceptions (41). Engagement also bridges the gap between abstractions and details (Karl Weick, personal communication). Engagement makes use of details, nuance, and the subtle. Details can herald early response to therapy or be an early herald of failure. Yet, focus on details without context is the definition of micromanagement details (Karl Weick, personal communication).

Bag-valve-mask (BVM) ventilation for the unprotected airway in a breathing patient is fraught with complications. One author (DvS) altered the methods used for BVM based on details from his field experience providing mouth-to-mouth ventilation to a breathing infant, adolescent, and adult. The feedback felt in the mouth guides when to stop the breath and start the next breath. That is why mouth-to-mouth ventilation rarely, if ever, causes emesis. Using detailed sensing with BVM, this method is used in a pediatric subacute facility and by special groups in the Special Operations Command (SOCOM) in the US and several NATO countries (42).

\section{HRO is "Knowledge by acquaintance"}

"To say that I am acquainted with an object when I have a direct cognitive relation to that object.When I speak of a cognitive relation here, I do not mean the sort of relation which constitutes judgment, but the sort which constitutes presentation (8). Acquaintance is not judgment. Therefore, the experience is not judgment. Experience is what happens to you, it changes you, but it is not you.

This is critical for engagement. Acceptance is the absence of judgment. Acceptance is also a critical element of comedy improvisation and is the gate for HRO improvisation. When we self-organize under intention, we are improvising. Otherwise, our responses are random at worse and trial-and-error at best; neither leads to learning. Also, in Dewey's pragmatism, acceptance intercedes between causation and action. In fact, acceptance is why you don't need causation.

\section{"HRO is a trajectory with flux and flow that continuously engages our experience. Too easily, we can plan and review for comparison from some fixed point where the vantage lets us see causation, real or putative."}

$\mathrm{HRO}$ is a trajectory with flux and flow that continuously engages our experience. Too easily, we can plan and review for comparison from some fixed point where the vantage lets us see causation, real or putative.

Experience by description: The illusion of experience. Experience is to interact with the environment without mediation. Some linger under the fallacy of experience when they are in close proximity or are well-read. It is the intimate give-and-take of corrective measures outsiders would call an error that creates the experience. Giving priority to the first thing a person thinks of, the availability construct, can lead to grave danger during the engagement. This problem is most clearly experienced with consulting physicians whose frame of reference comes from a medical specialty rather than the flux and mix-up from direct actions with a patient. A more subtle and treacherous illusion of experience occurs when an individual's identity forms from their perceived experience. These individuals do not entertain the questioning that a veteran of engagements actively seeks.

\section{Conclusion}

In the HRO, we engage with all our mind; any space could be liminal, unidentified as such, only because we are missing something. This is not nervousness but mental preparation for the early herald. When does early engagement of an outlier become pre- 
vention of the outlier?

An HRO utilizes experience, beliefs, and concepts.

- $\quad$ There is continuity of experience.

- Every experience takes up from those that have gone before and modifies those that come after.

- Experience helps with memory and recall.

Experience is in the affective domain of knowledge.

Beliefs are confirmed, disconfirmed, and modified by experience.

- Experience has a central role in fostering and supporting our beliefs.

Concepts aid the interpretation of our experience.

○ But it is the experience we call upon for how to use concepts.

\section{"We operate in open systems. The liminal incident entrains energy and resources. Entering the liminal state initiates the self-organizing that will form structure. Engagement starts the self-organization necessary to reach a preferred end-state."}

We operate in open systems. The liminal incident entrains energy and resources. Entering the liminal state initiates the self-organizing that will form structure. Engagement starts the self-organization necessary to reach a preferred end-state. Engagement need not be active involvement. Notification, monitoring, isolating are all forms of engagement.

We have what Karl Weick (personal communication) calls the "involuntary memory of protocols and routines, continuities with previous experience (we know with what we've known), and the past." We do not treat the past "in a temporal sense but in a figural sense in which it frames and categories and narrates a present liminal cue." This is our anchor to initiate engagement.

Acceptance of the situation and information is key. Doubt is necessary, but in the extreme of skepticism, we reject nearly everything in front of us. Doubt leads us to recheck and re-evaluate, remembering that our best facts and most reliable information are what we immediately generated.

HRO acts like a trajectory, moving in form and energy as the liminal event. "HRO is a trajectory of engagement that fuses now with the experience of then into simultaneous inquiry and redescription," Karl Weick (personal communication).

The HRO uniquely shapes engagement to move through and out of a liminal period. If it's liminal (which it often is), we engage with all our minds. In these events, our most reliable resources are our capabilities and our reasoning.

For a short time scale, HRO gives the reliability to conserve the organization's core functions. For longer time scales, HRO supports evolvability; the organization becomes new as the environment becomes new.

HRO accepts the actual world in its liminal state while constantly engaging toward a preferred world. We cannot substitute a virtual world or the desired world with the actual world. An HRO accepts the world as it is. Our experience supports our engagement. We make the world better.

\section{"HRO accepts the actual world in its liminal state while constantly engaging toward a preferred world. We cannot substitute a virtual world or the desired world with the actual world. An HRO accepts the world as it is. Our experience supports our engagement. We make the world better."}

\section{References}

1. Dewey J. The quest for certainty: A study of the relation of knowledge and action. New York, NY: Minton, Balch, and Co.; 1929.

2. James W. A Pluralistic Universe. New York, NY: Longman's, Green, and Co.; 1909.

3. University $H$. William James [Internet]. Harvard University; 2021 [cited 2021 March 14].

4. van Stralen D, Mercer T. The Art of Neonatology, the Art of High Reliability as a Response to COVID-19. Neonatology Today. 2021;16(2):74-83. doi: 10.51362/neonatology.today/202121627483.

5. James W. Essays in radical empiricism. Oxford, UK: Oxford Text Archive Core Collection; 1912.

6. Gaukroger S. Descartes: An intellectual biography. Oxford, UK: Clarendon Press; 1995.

7. Dewey J. Experience and Nature. New York, NY: Dover Publications, Inc; 1958.

8. Russell B. Knowledge by Acquaintance and Knowledge by Description. Proceedings of the Aristotelian Society. 1910(11):10828.

9. van Stralen D, Mercer TA. Flight Decks and Isolettes: HighReliability Organizing (HRO) as Pragmatic Leadership Principles during Pandemic COVID-19. Neonatology Today. 2020;15(7):113-22.

10. van Stralen D, McKay S, Mercer T. Pragmatic Leadership Practices in Dangerous Contexts: High-Reliability Organizations (HRO) for Pandemic COVID-19. Neonatology Today. 2020;15(8):109-17. doi: 10.51362/neonatology.

Readers can also follow NEONATOLOGY TODAY via our Twitter Feed @NEOTODAY 
today/20208158109117.

11. van Stralen D, Mercer TA. High Altitude Climbing, High Reliability, COVID-19, and the Power of Observation. Neonatology Today. 2021;16(1):68-79.

12. Dewey J. Reality as Experience. The Journal of Philosophy, Psychology and Scientific Methods. 1906;3(10):253-7.

13. Pulte H. Kant, Fries, and the Expanding Universe of Science. In: Friedman M, Nordmann A, editors. The Kantian legacy in nineteenth-century science. Cambridge, MA: MIT Press; 2006. p. 101-22.

14. Abbott A. Chaos of disciplines. Chicago, IL: University of Chicago Press; 2010.

15. Gardner S. Routledge philosophy guidebook to Kant and the Critique of pure reason. New York, NY: Routledge; 1999.

16. Kulyk O. Chaos in Heinrich Rickert's philosophy. Scientific and theoretical almanac «Grani». 2019;22(8):37-46.

17. Sloan PR. Performing the Categories: Eighteenth-Century Generation Theory and the Biological Roots of Kant's A Priori. Journal of the History of Philosophy. 2002;40(2):229-53.

18. Larsen SE. The Lisbon earthquake and the scientific turn in Kant's philosophy. European Review. 2006;14(3):359-67. doi: 10.1017/s1062798706000366.

19. Pereboom D. Kant's Transcendental Arguments: Stanford University; 2019 [cited 2021 March 10]. Spring 2019 Edition:[Available from: https://plato.stanford.edu/archives/ spr2019/entries/kant-transcendental/

20. Oliver K. Earthquakes: Deconstructing Humanitarianism. Derrida Today 2017;10(1):38-50.

21. Szakolczai A. Liminality and experience: Structuring transitory situations and transformative events. International Political Anthropology. 2009;2(1):141-72.

22. Smith NK. A Commentary to Kant's "Critique of Pure Reason". A Commentary to Kant's 'Critique of Pure Reason'. Lonon, UK: Palgrave Macmillan; 2003. p. 1-78.

23. Whitehead AN. Science and the modern world. New York, NY: The Macmillan Company; 1925.

24. James W. Abstractionism and 'Relativismus. The Meaning of Truth. New York, NY: Longman Green and Co 1911. p. 246-71.

25. DeMaio J, Parkinson S, Leshowitz B, Crosby J, Thorpe JA. Visual scanning: Comparisons between student and instructor pilots. Tempe, AZ: Arizona State University, Tempe 1976.

26. Dreyfus SE, Dreyfus HL. The scope, limits and training of three models of aircraft pilot emergency response behavior. Berkeley, CA: Operations Research Center, Univ. of California, Berkeley, Force UA; 1979 February 1979. Report No.

27. Dreyfus HL, Dreyfus SE. Uses and abuses of multi-attribute and multi-aspect model of decision-making. In: Department of Industrial Engineering and Operations Research UoC, Berkeley, editor. 1977.

28. Weick KE. Drop your tools: An allegory for organizational studies. Administrative science quarterly. 1996;41(2):301-13.

29. Leddy T. Dewey's Aesthetics. In: Zalta EN, editor. The Stanford Encyclopedia of Philosophy: Stanford University; 2020.

30. Hickman LA. Pragmatism as Post-postmodernism. New York,NY: Fordham University Press; 2019.

31. van Stralen D, Mercer TA. During Pandemic COVID-19, the High-Reliability Organization (HRO) Identifies Maladaptive Stress Behaviors: The Stress-Fear-Threat Cascade. Neonatology Today. 2020;15(11):113-24.

32. van Stralen D, Mercer TA. Pandemic COVID-19, the High-Reliability Organization (HRO), and the Ecology of Fear. Neonatol- ogy Today. 2020;15(12):129-38.

33. Krathwohl DR, Bloom BS, Masia B. Taxonomy of Educational Objectives Handbook II: Affective domain. New York: NY: David McKay Company; 1964.

34. van Stralen D, Gambino W. Error as a Faulty Failure Signal. Neonatology Today. 2020;15(9):114-7.

35. van Stralen D, Mercer TA. Pragmatic High-Reliability Organizations (HRO) Modulate the Functions of Stress and Fear Behaviors During Pandemic COVID-19: The Stress-Fear-Threat Cascade. Neonatology Today. 2020;15(10):126-34.

36. van Stralen D, Byrum SL, Inozu B. High Reliability for a Highly Unreliable World: Preparing for Code Blue through Daily Operations in Healthcare: CreateSpace Independent Publishing Platform; 2017.

37. van Stralen D, McKay S, Williams GT, Mercer TA. Tactical Improvisation: After-Action/Comprehensive Analysis of the Active Shooter Incident Response by the San Bernardino City Fire Department December 2, 2015. San Bernardino, CA: San Bernardino County Fire Protection District; 2017.

38. Morris DJ. The evil hours: A biography of post-traumatic stress disorder. New York, NY: Houghton Mifflin Harcourt; 2015.

39. McKay S, Johnston J, Smith G, Briganti D, Howel B, Ditzel R, et al. Refining Operational Vertical Mobility. Journal of High Threat \& Austere Medicine. 2021:1-19.

40. van Stralen D. Pragmatic HRO during Pandemic COVID-19. Neonatology Today. 2020;15(4):3-9.

41. Weick KE. Organizing for transient reliability: The production of dynamic non-events. Journal of contingencies and crisis management. 2011;19(1):21-7.

42. van Stralen D, Westmoreland T. Management of a Mechanical Ventilator Using Patient Calm as an Endpoint. Special Operations Medical Association Scientific Assembly (SOMSA); December 8-11, 2014; Tampa, FL: Special Operations Medical Association (SOMA); 2014.

Disclosure: The authors have no disclosures.

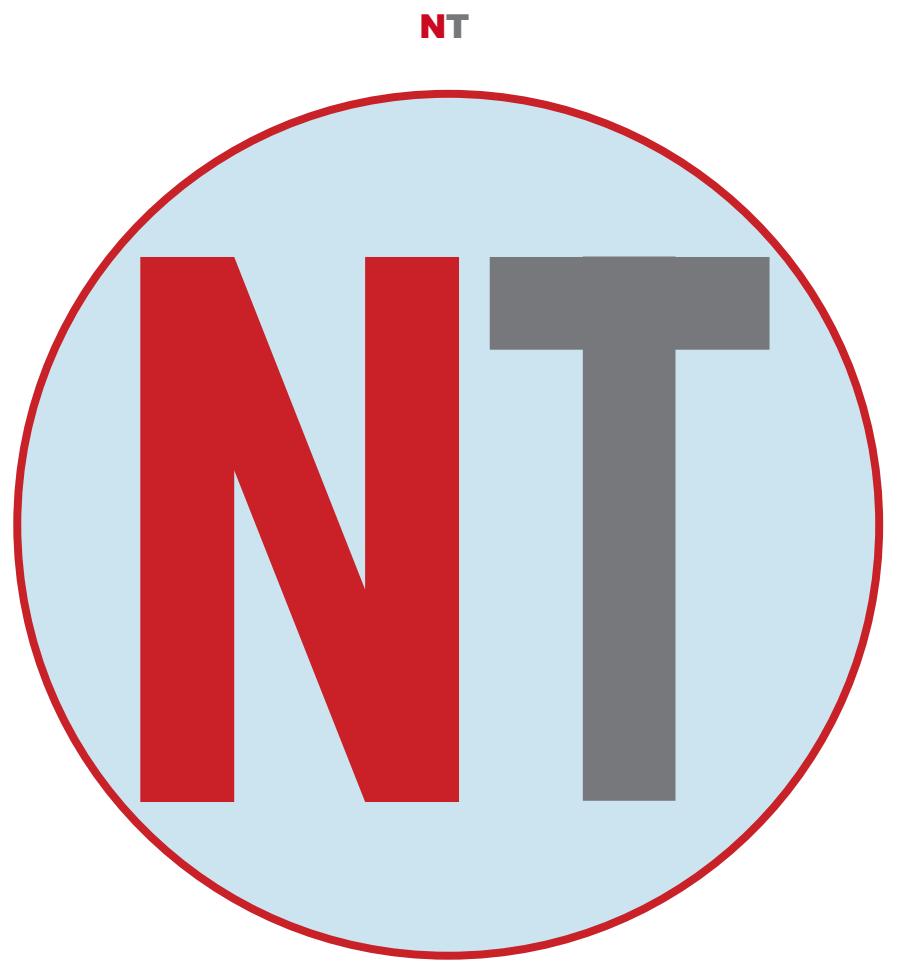




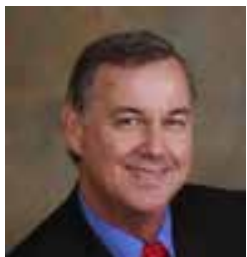

Daved van Stralen, MD, FAAP

Associate Professor, Pediatrics

Department of Pediatrics

Loma Linda University School of Medicine

11175 Campus Street

CP-A1121

Loma Linda, CA 92350

Email: DVanStra@llu.edu

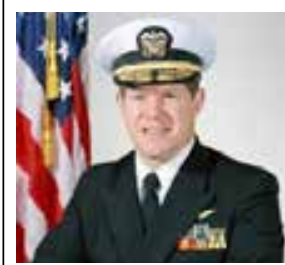

Thomas A. Mercer

Rear Admiral

United States Navy (Retired)

\section{Acknowledgments}

Karl Weick- review and editing, Rensis Likert Distinguished University Professor of Organizational Behavior and Psychology, Emeritus, University of Michigan

Errol van Stralen, Ancora Education

Sean McKay, Element Rescue, LLC

William J. Corr, formerly with the Los Angeles City Fire Department, now deceased

\section{Coping During COVID-19

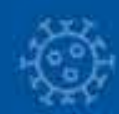

Tets:

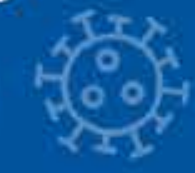

Targeted interventions to improve the mental health of parents, infants, families, and providers

\section{BONDING WITH YOUR BABY}
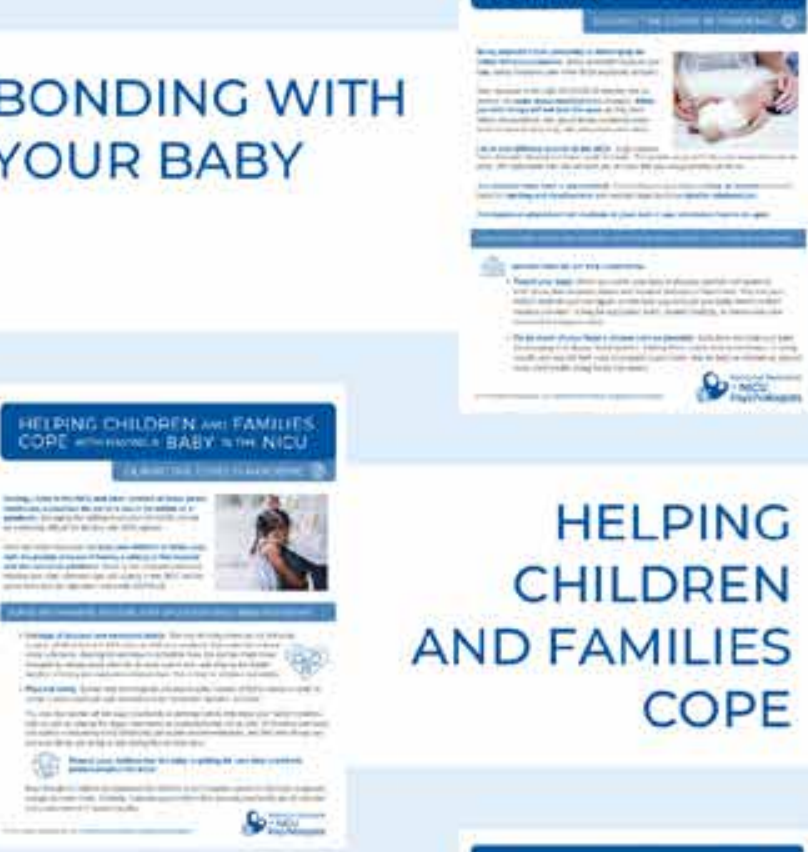

\section{HELPING \\ CHILDREN \\ AND FAMILIES COPE}

\section{CAREGIVERS NEED CARE $\mathrm{TOO}$}

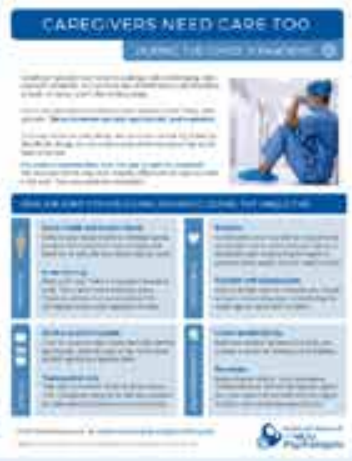

Readers can also follow NEONATOLOGY

\author{
via our Twitter Feed
} @NEOTO
National Network

of NICU Psychologists

nationalperinatal.org/psychologists 